Artigo

\title{
MEMÓRIAS DE SABERES TRADICIONAIS NO ANTIGO QUILOMBO CABULA (SALVADOR - BAHIA): PERCURSOS ENTRE NARRATIVAS DE PARTO
}

\author{
MEMORIES OF TRADITIONAL KNOWLEDGE IN THE OLD QUILOMBO CABULA \\ (SALVADOR - BAHIA): ROUTES BETWEEN CHILDREN NARRATIVES \\ RECUERDOS DE CONOCIMIENTOS TRADICIONALES EN LA ANTIGUA CABULA \\ DE QUILOMBO (SALVADOR - BAHIA): RUTAS ENTRE LAS NARRATIVAS \\ INFANTILES
}

\author{
Mary Lúcia Souto Galvão \\ Ticiana Osvald Ramos \\ Maiara de França Gomes \\ Fernanda de Santana Barros \\ Francisca de Paula Santos da Silva
}

\section{Resumo}

Este artigo apresenta a discussão teórica e metodológica adotada na pesquisa de doutorado homônima. Partimos do território quilombola do Cabula, ancorando primeiramente na discussão sobre os processos de colonização, colonialidade e contra colonização e como influenciam o campo da saúde. A segunda sessão aporta na incidência desses processos sobre o oficio das Parteiras Tradicionais e no contexto da gestação, parto e pós-parto. Por fim, atracamos nos aspectos metodológicos em torno das narrativas como resistência contra colonizadora.

\begin{abstract}
This article presents the theoretical and methodological discussion adopted in the homonymous doctoral research. We started from the quilombola territory of Cabula, anchoring primarily in the discussion about the processes of colonization, coloniality and against colonization and how they influence the field of health. The second session focuses on the impact of these processes on the role of Traditional Midwives and in the context of pregnancy, childbirth and postpartum. Finally, we dock in the methodological aspects around the narratives as resistance against colonizers.
\end{abstract}

\section{Resumen}

Este artículo presenta la discusión teórica y metodológica adoptada en la investigación doctoral homónima. Partimos del territorio quilombola de Cabula, anclando principalmente en la discusión sobre los procesos de colonización, colonialidad y contra la colonización y cómo influyen en el campo de la salud. La segunda sesión se centra en el impacto de estos procesos en el papel de las parteras tradicionales y en el contexto del embarazo, el parto y el posparto. Finalmente, incluimos los aspectos metodológicos en torno a las narrativas como resistencia contra los colonizadores.

Palavras-chave: Colonialidade; Saberes Tradicionais; Parteiras; Cabula; Medicalização.

Keywords: Coloniality; Traditional Knowledge; Midwives; Cabula; Medicalization.

Palabras clave: Colonialidad; Conocimiento tradicional; Parteras; Cabula; Medicalización. 


\section{INTRODUÇÃO}

Como as mulheres das comunidades do Cabula enunciam em suas narrativas, as vivências dos cuidados durante a gestação, parto e pósparto? Tal questão norteia a pesquisa de doutoramento cujos passos nos propomos contar neste artigo. Partindo desse problema, entendemos o Cabula como território de saberes tradicionais que "(...) pode falar de si mesmo, sua origem, sociabilidade e sua existência de lugar de afirmação africana e africanobrasileira" (NICOLIN, 2016 p. 108-109). A população do Cabula, remanescente de quilombos, apresenta em seu território, modos singulares e, ao mesmo tempo, plurais de cuidar da saúde, em contraposição a colonialidade inerente ao seu processo de composição, responsável pela marginalização e a desvalorização dos conhecimentos tradicionais e populares.

Os territórios quilombolas dispõem de uma identidade singular, elo entre seus moradores e destes com a terra, chão das relações comunitárias dadas por interesses comuns, com a participação de suas lideranças e a ancestralidade ali manifestada. Os quilombos são coletividades organizadas que expressam a luta pela liberdade, influenciadas pela geografia, a ecologia e os campos de forças sociais inerentes ao contexto de insubordinação e ocupação deste espaço, não dispondo de regras únicas, concepções unidimensionais (SILVA, 2000; SANTOS, 2015). Manifestando sobretudo a pluralidade, como traço de reconhecimento da diversidade e da comunidade em seus deuses e deusas, formas de relacionamento interpessoal e com os recursos naturais, como aponta Bispo (SANTOS, 2015). Assim, devem ser reconhecidos como elementos identitários para essas comunidades (MUNANGA, 1988) que constroem vínculos vitais entre esses e seus antepassados, que habitaram e morreram na terra da qual dependem a sobrevivência individual e coletiva, como o corpo individual e social que serve de suporte material para todas as identidades.

Pensar em quilombos implica em multiplicidade de significados com reconhecimento na comum-unidade por serem diversos enquanto "acampamento guerreiro na floresta" (LOPES; SIQUEIRA; NASCIMENTO, 1987 apud NICOLLIN, 2014), ou seja, um modo de organização de resistência material e simbólica ("acampamento") conformada tanto pelo enfrentamento ("guerreiro") como pelo posicionamento propositivo de convivência no espaço físico e natural ("floresta"). No caso do Cabula, sua ocupação sócio espacial ocorreu desde o período colonial, quando era conhecido como "Miolo", por estar localizado no centro da cidade de Salvador. A região era coberta de Mata Atlântica, sendo de difícil acesso (ALMEIDA, 2007). Este cenário de refúgio passa a ser identificado pela palavra Cabula, "mistério" no idioma banto, legado étnico das regiões do Congo e Angola (NICOLIN, 2014).

A perspectiva decolonial indica a necessidade de considerar a pluralidade histórica dos remanescentes de quilombo para construir estratégias de interlocução entre as comunidades e o Estado, para registrar, salvaguardar e resgatar os conhecimentos tradicionais locais, no sentido das confluências ${ }^{1}$

\footnotetext{
${ }_{1}^{1}$ Para Bispo (SANTOS, 2015, p. 89): "Confluência é a lei que rege a relação entre os elementos da natureza e nos ensina que nem tudo que se ajunta se mistura, ou seja, nada é igual. Por assim ser, a confluência rege também os processos de mobilização provenientes do pensamento plurista dos povos politeístas.", os povos contra coloniais.
} 
apontadas por Antônio Bispo (SANTOS, 2015). Assim, propomos neste estudo mergulhar no território quilombola para registrar memórias dos saberes tradicionais de parteiras, a partir das narrativas de mulheres que vivenciaram os cuidados durante gestação, parto e pós-parto por essas guardiãs.

De acordo com Walsh (2008), a referência para este processo está nos movimentos sociais e coletivos, considerando povos historicamente subalternizados na sua própria existência para construir outros modos de viver, poder e saber. O caráter totalitário da exploração colonial que foi responsável pela desqualificação dos saberes das Parteiras Tradicionais e demais agentes de cuidado comunitário despertou o desejo de registrar as memórias da forma de cuidar da gestação, parto e pós-parto nas comunidades do Cabula, como estratégia de contra-colonização (SANTOS, 2015).

Nesse artigo, dividiremos a trilha percorrida até aqui passando por questões em torno dos processos de colonização, colonialidades e contra colonização, especificidades das parteiras e seus saberes tradicionais para, por fim, compartilhar propositivamente as implicações metodológicas que afirmam a "narrativa-ção" como resistência.

\section{COLONIZAÇÃO, COLONIALIDADES, CONTRA COLONIZAÇÃO E O CAMPO DA SAÚDE}

O colonialismo estabeleceu uma relação política e econômica na qual a soberania de um povo está na dominação de outros povos ou nações, atribuindo à "matriz" o poder de império e aos subalternos a responsabilidade de sua sustentação. Reforçando as estruturas de poder estabelecidas, a colonialidade se refere a um padrão que emergiu como resultado do colonialismo moderno. Uma vez que não está limitada a uma relação formal de poder, se relaciona também à lógica do trabalho, o conhecimento, às autoridades legítimas e a articulação das relações intersubjetivas, sendo ainda regulada pelo mercado capitalista mundial e fortalecida pela ideia de raça e do racismo ${ }^{2}$. Assim, apesar do colonialismo preceder a colonialidade, esta sobrevive ao colonialismo, se mantendo viva na autoimagem dos povos, nas aspirações dos sujeitos, na cultura, nos sentidos comuns, em textos didáticos, na construção das ciências, nos critérios para o bom trabalho acadêmico e em muitos outros aspectos de nossa experiência moderna (TORRES, 2008).

O processo da modernidade, como parte da construção colonialista, marginalizou, omitiu e silenciou os saberes tradicionais, impondo a superioridade do saber europeu através da colonialidade do poder que representa uma lógica classificação étnica da população, operando como centro mundial do capitalismo, colonizando o mundo através da racionalidade da ciência positivista (QUIJANO, 2005). O saber científico eurocentrado criou o método científico ocidental, que tinha como princípios norteadores, a razão e o método, suprimindo o corpo, as emoções e a espiritualidade, estabelecendo a separação simbólica entre o homem e a natureza, desencadeando outras dicotomias próprias que construíram a ideia de que a melhor forma de vida é a do homem branco, colonizador, europeu (SEGATO, 2014; NASCIMENTO, 2010; QUIJANO, 2005).

Os colonizadores submeteram a América Latina, a África e a Ásia a estruturas de dominação, fragilizando seu imaginário como forma de

\footnotetext{
2 Para Anibal Quijano (2005), o discurso de raça foi uma estratégia utilizada como instrumento de dominação, através do questionamento original sobre os povos indígenas terem ou não uma alma, para posteriormente estabelecer distinções entre as raças, classificando-os.
} 
subalternizar, reprimindo os modos de produção de conhecimentos e saberes. Desse modo, a raça converteu-se no primeiro critério de classificação da população mundial em níveis, lugares e papéis, para estruturar o poder do "novo mundo" (QUIJANO, 2005). Tal processo implicou na redução das identidades singulares indígenas e africanas e a criação de uma identidade colonial negativa. A violência epistêmica da negação do estatuto de humanidade e de todos os direitos decorrentes desse, comprometeu a liberdade dos seres, bem como, a história dos indivíduos e coletividades subalternizadas (WALSH, 2008), sendo co-partícipe, ainda, uma geopolítica linguística ${ }^{3}$ (MIGNOLO, 2005).

Reconhecer a colonialidade do poder (QUIJANO, 1989) por um lado, denuncia "a continuidade das formas coloniais de dominação após o fim das administrações coloniais" e, por outro, possui uma capacidade explicativa que atualiza e contemporiza os processos, que supostamente teriam sido apagados, assimilados ou superados pela modernidade (GROSFOGUEL, 2008), como um fetichismo epistêmico e uma geopolítica "apropriada" do conhecimento (OLIVEIRA; CANDAU, 2010) ou colonialidade do saber.

O conceito de raça foi criado para inferiorizar indígenas e africanos, lhes negando o legado intelectual e histórico, reduzindo-os a categoria de primitivos e irracionais. Para fragilizar esses povos, os colonizadores os codificaram, através da cor e de traços fenotípicos, legitimando as relações de dominação impostas pela conquista da América, atribuindo uma perspectiva eurocêntrica de conhecimento superior a partir da elaboração teórica da ideia de raça como uma naturalização dessas relações coloniais de dominação entre europeus e não europeus. A ordem hegemônica da expansão do domínio colonial da Europa sobre o mundo atuou numa lógica binária, dualista e etnocêntrica (QUIJANO, 2005).

A decolonialidade implica em considerar as lutas dos povos historicamente subalternizados para a construção de novos modos de viver, de poder e de saber, objetivando dar visibilidade às lutas contra a colonialidade a partir de suas práticas sociais, epistêmicas e políticas, ultrapassando a transformação da descolonização para reconstruir o seu poder e o saber (WALSH, 2005 p.13 apud OLIVEIRA; CANDAU, 2010). Mignolo (2005) destaca que, o "pensamento-outro" caracterizado como decolonialidade se expressa na diferença colonial, como um reordenamento da geopolítica do conhecimento em duas direções: a crítica da subalternização e a invisibilidade de outros saberes, considerando a colonialidade como constitutiva da modernidade.

A dominação produz vítimas, de muitas maneiras, violência que é interpretada como um ato inevitável e sacrifício. O sentimento de superioridade tem como consequência a obrigação de desenvolver os mais primitivos, como exigência moral. O herói civilizador reveste suas próprias vítimas da condição de serem holocaustos de um sacrifício salvador, como o índio colonizado, o escravo africano, as mulheres domesticadas, a destruição ecológica. Essa lógica coloca a modernidade e seus discursos como processos emancipatórios, culpabilizando "os outros" (LANDER, 2005).

\footnotetext{
${ }^{3}$ As línguas coloniais estabeleceram o monopólio linguístico, desprezando as línguas nativas e, como consequência, subvertendo ideias, imaginários e as próprias cosmovisões nativas fora da Europa.
} 
Pensando nas repercussões desses processos sobre o campo da saúde, percebemos a existência de uma hegemonia da biomedicina ${ }^{4}$, traduzida na centralidade da doença, dos hospitais e dos profissionais médicos. Visualizamos as cicatrizes da colonialidade nas relações construídas cotidianamente no interior dos hospitais, nos quais a categoria médica, oriunda de classe social favorecida, se comporta como no século XVIII, impondo o "saber dominante" às outras categorias profissionais, na lógica autoritária e hegemônica, ocupando sempre os melhores espaços e salários.

No campo da assistência ao parto, o modelo hegemônico pode ser reconhecido como medicalizado (RAMOS, 2013) ou tecnocrático (DAVISFLOYD, 2001), estabelecidos ao longo de um processo histórico de intensas lutas entre a crescente classe médica, oriunda de uma elite rica, masculina e branca, representando o saber legítimo e oficial e as cuidadoras tradicionais, parteiras em uma perspectiva plural, ou mulheres profissionalizadas, obstetrizes e enfermeiras obstetras (EHRENREICH; ENGLISH, 1976).

O hospital como local institucionalizado de assistência ao parto pode ser considerado também um dispositivo da colonialidade do saber, se sobrepondo aos saberes populares reproduzindo a hierarquização e legitimando um conhecimento marcado por um forte viés de gênero, caracterizado por uma biomedicina historicamente masculina (MELO, 2013). Para os médicos esse é o lugar por excelência de reconhecimento de seus méritos, da sua importância e conhecimentos, se auto definindo pelo poder/saber sobre a vida e a morte, ou biopoder (FOUCAULT, 2002), enquanto a categoria de enfermagem se legitimaria pelo cuidar (SILVA, 2006). Nesse espaço o cuidado desempenhado pelas enfermeiras convive sob o olhar autoritário da categoria médica, que desqualifica essa função essencial.

Os conflitos travados no ambiente hospitalar decorrem dentre outros fatores, das relações de poder que foram construídas ao longo do processo de legitimação da colonialidade. No contexto da assistência obstétrica, as mulheres, principalmente negras, que deveriam ser cuidadas, são muitas vezes vítimas da violência simbólica, verbal, psíquica, física e institucional permeadas pelas disputas entre aqueles que deveriam ser agentes cuidadores ${ }^{5}$.

\footnotetext{
4 "(...) é uma instituição global e institucionalizada; assume o paradigma científico que é tido como único, caracterizando uma ordem moral transcendente, de uma base materialista fundada na natureza (o que significa o reino físico); possui orientação reducionista radical, não 38 admitindo outros paradigmas para além das dicotomias que compreende (natural/não-natural, feminino/masculino, corpo/mente, etc), incluindo os tipos de intervenções médicas como "pesadas" ou "leves"; constrói os objetos terapêuticos sem legitimação da experiência do sofrimento, mas como problemas técnicos independentes da coletividade, a unidade é o indivíduo; assume um anti-autoritarismo calcado em procedimentos bioéticos; assume a idéia de progresso e uma racionalidade técnica; ocasiona a medicalização como expansão da racionalidade técnica para experiências humanas profundas, sendo essa sua característica mais controversa; implica na profissionalização altamente especializada; promove o paciente à condição de consumidor e transforma o cuidado em mercadoria, estabelecendo profundas relações de compromisso com o Estado." (RAMOS, 2013).

${ }^{5}$ A violência obstétrica, que agregada as violências citadas no texto, vem sendo cada vez mais apontada como resultado do modelo obstétrico hegemônico que, no caso brasileiro, se traduz em altas taxas de cesarianas e intervenções realizadas sem indicação (Kristeller, episiotomia, amniotomia, indução com ocitocina, entre outras), mortalidades e morbidades associadas ao cuidado ineficaz, ausência de adequada rede assistencial, bem como experiências subjetivas marcadas por impressões e experiências negativas (RAMOS, 2013).
} 
Nesse contexto de colonialidade do saber, resistem as Parteiras Tradicionais, bem como as memórias de suas práticas e saberes (SOARES, 2016). Essa é a contra colonização: "(...) todos os processos de resistência e de luta em defesa dos territórios dos povos contra colonizadores, os símbolos, as significações e os modos de vida praticados nesses territórios." (SANTOS, 2015, p. 48). Conhecer esses elementos representa parte de um processo que caminha em direção da valorização das cuidadoras tradicionais.

\section{VALORIZAÇÃO DAS PARTEIRAS E SABERES TRADICIONAIS}

O campo da parteira tradicional foi estereotipado e, no Brasil associado às mulheres, negras, indígenas, pobres, idosas, analfabetas, leigas e curiosas. Esse estereótipo subjugou o saber acumulado por essas parteiras e contribuiu para reafirmar o quanto estariam distantes do que a ciência moderna legitima (EHRENREICH; ENGLISH, 1976). A parteria tem cor e as parteiras que não tiveram reconhecimento do seu oficio, não recebem recurso do Estado pelo trabalho que desenvolvem. São mulheres negras ou indígenas, que também vivenciam os problemas de suas comunidades onde são reconhecidas pelo grupo como agentes de saúde e mediadoras de conflitos referentes às questões econômicas, sociais, de gênero e violências (SOARES, 2016).

As Parteiras Tradicionais adquirem conhecimentos empíricos sobre a fisiologia do corpo da mulher através das habilidades adquiridas ao longo do tempo, tornando-se mestre de seu ofício. A concepção do parto assistido por Parteiras Tradicionais está associado com a espiritualidade e a natureza, através de amuletos e talismãs, orações, cânticos religiosos e rituais, incluindo a utilização de ervas medicinais e da construção de vínculos afetivos com a mulher e sua família (GALVÃO, 2001; BARROSO, 2009).

O uso de ervas constitui práticas do cuidado presentes no cotidiano das comunidades quilombolas como parte do fazer tradicional enquanto expressão de fé e religiosidade. Essas manifestações indicam um legado da memória da tradição oral de um povo (ROSA, 2013).

Entre o século XVI e o século XVIII, os partos eram realizados em casa, de maneira não intervencionista, assistidos por mulheres também conhecidas como 'comadres', 'aparadeiras' e 'curiosas', reconhecidas em suas comunidades, detentoras de um saber empírico transmitido de geração a geração a partir de uma transmissão oral e simbólica, ancoradas nas relações de parentesco, numa rede de mulheres a qual se reservava o mistério do nascimento, onde o cuidado era carregado e imantado, pelo respeito, pelo sagrado e especialmente pela delicadeza gestual (GALVÃO, 2001).

Para Ramos (2013), a parteira representa:

Personagem quase universalmente mulher, em geral, com certa experiência em parir e ajudar outras a parir, mereceu muitos registros históricos nas artes e ciências. Essa personagem que, para definir tentativa e provisoriamente, ajudava outras mulheres principalmente no momento do parto, mas possivelmente também na gestação, no período pós-parto e outras ocasiões de distúrbios pessoais e familiares, recebe diversas alcunhas, posições e papéis de acordo com tempos e espaços distintos (RAMOS, 2013, p.115). 
Até 1832, antes da institucionalização da medicina no Brasil, as parteiras estavam situadas entre os praticantes de medicina considerados populares, não acadêmicos (BARRETO, 2008). Nesse período o trabalho das parteiras era abrangente, não se restringia a ajudar outras mulheres a darem à luz, elas exerciam uma série de outras funções no aspecto do cuidado. Dentre outras atribuições, elas cuidavam da saúde das mulheres, gestantes e puérperas, participavam dos primeiros cuidados com o bebê, conhecendo o uso de chás e ervas.

Em nome da ciência e das reformas, os médicos estigmatizaram as parteiras, ridicularizando-as como pessoas sujas, ignorantes e incompetentes. Elas foram acusadas e consideradas responsáveis pela prevalência, da sepse puerperal e oftalmia neonatal, e proibidas de receber o treinamento das técnicas preventivas apropriadas (EHRENREICH, ENGLISH, 1976).

Estudos feministas afirmam que a história dessas mulheres foi revelada, a luz da colonialidade do saber, identificando que o parto realizado no ambiente familiar e assistido por essas mulheres, não provocou tantas mortes e nem produziu os resultados que foram divulgados pela categoria médica. Os problemas ocorridos entre os profissionais indicam que a chegada dos cirurgiões e médicos, no campo da assistência obstétrica, resulta do esforço para legitimação da categoria médica com o propósito de fragilizar a autoridade das parteiras sobre o ritual do parto e nascimento (BARRETO, 2008).

As Parteiras Tradicionais continuam enfrentando dificuldades no atendimento ao parto domiciliar em razão de fatores, tais como, as vulnerabilidades inerentes às condições sociais às quais elas e as mulheres que Ihe procuram estão inseridas; a falta de apoio da rede da atenção básica que permanece ignorando sua atuação a despeito das políticas públicas que recomendam sua inserção no âmbito do SUS; e por fim, pela discriminação que sofrem por parte dos profissionais de saúde (GALVÃO, 2001).

A maioria da população brasileira urbana, acredita que os cuidados oferecidos pelas Parteiras Tradicionais constitui um atendimento de baixa qualidade em relação às práticas da biomedicina e que somente as mulheres domiciliadas em zona rural de difícil acesso procuram seus cuidados (MOTT, 2002). No pano de fundo dessas relações, persiste o embate entre os saberes sintéticos e orgânicos, fundamentados em aparência e realidade, para a acumulação (ter) ou a bioenteração (ser), conforme relata Bispo (SANTOS, 2015). A Biointeração, a relação harmoniosa e prazerosa, holística entre os seres e os processos de seus ciclos reprodutivos, orienta a dança da vida entre as repetições cíclicas do nascimento. Assim, não existiria lixo, morte ou fim, mas o curso da vida, como a confluência das águas.

As memórias coletivas constituem conhecimento ancestral associado à biodiversidade e pertencentes às comunidades tradicionais, que são dominadas por países que monopolizam $70 \%$ da flora, fauna e ecossistema do planeta (BERTOLDI, 2014). Essa situação se aplica a população do Cabula que sofre incontáveis expropriações e vem perdendo para a indústria farmacêutica seus conhecimentos milenares e intergeracionais a respeito da utilização dos recursos naturais em favor da saúde, implicando em impactos culturais, sociais, econômicos e ambientais (NICOLIN, 2016).

Sendo assim, a nossa proposta é identificar a memória de saberes de parteiras, de cuidados com a gestação, parto e pós-parto, destacamos os valores míticos e sagrados, fincados nesse território de ancestralidade africano- 
brasileira, onde as religiões de matriz africana permanecem vivas no cotidiano manifestados pelas danças, cânticos, rituais, dentre outras práticas herdadas e cultivadas com a fé que emana da tradição. Existe uma forte relação entre cultura, fé e tradição no campo da saúde e da assistência parto, enquanto ritual de espiritualidade que vem guardando seus mistérios (Cabula) ao longo dos séculos.

\section{NARRATIVA-AÇÃO COMO RESISTÊNCIA: aspectos metodológicos}

Do Cabula partimos como espaço material e simbólico reconhecendo-o como território quilombola, que Bertagnolli descreve como (2015): "(...) um tributo à força da resistência africana e afro-brasileira que não se rendeu a servidão colonial e até por isso que estes dois conceitos, de quilombo e resistência, são fundamentais para a compreensão da história do povo negro no Brasil.". Esse reconhecimento, segundo Nicolin (2016), passa pela consciência da identidade do grupo, em sua experiência singular de pertencimento, que é percebido na divisão espacial oficial do Cabula, que não condiz com o entendimento dos moradores: "(...) a lógica do Ocidente não consegue dar conta do que o corpo do Cabuleiro guarda como tempo vivido, por isso se admite a existência de vários Cabulas." (NICOLIN, 2016).

Até 1960, o Cabula vivia enraizado no contexto rural, na busca de sua afirmação sócio existencial africana de repatrimonialização e socialização 6(MOURA, 1981 apud NICOLIN, 2016, p.120). Nicolin (2016) propõem um recorte em duas temporalidades:

o Cabula antes de 1960, a partir das experiências vividas pelos ancestrais quilombolas e ancestrais fundadores das comunidades da tradição oral africana; e a outra, o Cabula depois de 1960, a partir da chegada das referências do mundo urbano-industrial que modificaram sensivelmente as características da natureza de mata cabuleira, ao lhe impor, sem negociação, a convivência com o concreto (cimento) para fins de modernização da Cidade do Salvador (NICOLIN, 2016 p.100).

As obras no Cabula pós anos 60 aprofundaram paradoxos entre os valores tradicionais dessa população e o discurso oficial, promovendo a modernidade salvacionista, em nome do "desenvolvimento" (GOUVEIA, 2010). Em contrapartida, houve o enfrentamento ao sistema ideológico colonialista como resistência para preservação da cultura e organização político-social, oriundas de diferentes sociedades africanas: Congo-Angola, Gege Daomé, Nagô lorubá, frutificando as vivências africanas impregnadas do simbólico cultural da "pequena" África reterritorializada no Brasil. Assim, a força mística guerreira dos ancestrais continua a se manifestar na arte, música, dança, culinária e religiões de matriz africana, com forte borbulhar da existência social cabuleira (NICOLIN, 2014) como duplo modo de resistir e existir.

Os territórios religiosos foram e continuam sendo muito importantes nesse sentido, inicialmente na clandestinidade sofrendo perseguição (NICOLIN 2016; MUNANGA,1988) porém é fundamental reconhecer que "é impossível narrar a história do Cabula sem descrever os feitos inaugurais das casas das matrizes

\footnotetext{
${ }^{6}$ As abordagens sócio antropológicas sobre os aspectos organizativos e políticos dos quilombos se iniciaram a partir da década de 1970 (MOURA, 1981 apud NICOLIN, 2016, p.120).
} 
africanas congo-angola, nagô e jeje" (NICOLIN, 2016). A memória desses territórios representam espaços de trocas compartilhadas em comunidade para legitimar sua identidade grupal. (MUNANGA, 1988).

A população quilombola também herdou de seus antepassados saberes tradicionais no cuidado com a saúde que mesmo enfraquecidos, a partir da implementação da biomedicina, permanecem enraizados em sua memória. Esses saberes foram transmitidos por seus antepassados e adquiridos em espaço familiar e/ou comunitário (SOARES, 2016). Essas práticas e saberes tradicionais constituem formas de cuidados, que permanecem em comunidades rurais e periféricas das grandes cidades, como expressão viva do patrimônio dessas populações (MARIN; CUMIN, 2017).

Embora reconhecendo o grande poder do processo de colonização incidindo sobre as tradições, constata-se que os saberes e práticas dos quilombos permanecem vivos, como saberes populares (SILVA, 2000). Uma pesquisa realizada em 2015, revelou que a população deste bairro mantém preservado o uso de ervas, sementes e frutos como recursos complementares no controle dos sintomas de Hipertensão Arterial Sistêmica (HAS) e Diabetes Mellitus (DM). Dos 61 (sessenta e um) portadores de HAS e DM, 40 (quarenta) informaram que faziam uso regular de chás e sucos para o controle dessas patologias (ROCHA; SILVA, 2017). O uso de ervas medicinais está relacionado aos costumes de familiares, amigos e vizinhos reforçando a ideia da sabedoria popular ser transmitida oralmente, de geração a geração (FONTENELE, et al. 2013).

Até a década de 1970, não existiam hospitais no Cabula, assim infere-se que a cultura do parto e nascimento ainda era preservada, com suas características de evento familiar, doméstico sob cuidados de parteiras e cuidadoras tradicionais. A implantação do Hospital Geral Roberto Santos (HGRS) como marco da biomedicina é uma referência de mudanças de valores nos sentidos e significados da gestação e parto, representados por uma instituição hospitalar de grande porte com seu aparato tecnológico, profissional, ambiência e discurso hegemônico. O hospital trouxe uma nova configuração ao Cabula, uma vez que a biomedicina implementou a vigilância, como parte integrante do modelo de atenção para controlar os processos de adoecimentosaúde e ciclos de vida, reduzindo de modo estrutural a autonomia dos sujeitos.

Como local oficial e institucionalizado de assistência ao parto, este pode ser considerado um dispositivo da colonialidade do poder/saber, na medida em que, se sobrepõe às práticas e conhecimentos tradicionais, reforçando a hierarquização. Assim, reafirma-se um tipo de conhecimento marcado por um forte viés de gênero, uma vez que a biomedicina é um espaço historicamente masculino, fortalecendo a ideia de que as mulheres constitui uma categoria social mais vulnerável à medicalização. Incidindo sobre a vida cotidiana, encontra eco na formação das sociedades disciplinadoras, tendo na instituição médica um dispositivo normatizador dos saberes e práticas, sendo o hospital a esfera mais marcante desse biopoder (FOUCAULT, 2001; VIEIRA, 1999).

É neste território híbrido, de herança quilombola, mas que também sofreu inúmeras desapropriações pela colonialidade, que nasceu o interesse em resgatar fragmentos de memórias dos cuidados com as mulheres durante a gestação, parto e pós-parto realizados por PT. Alguns relatos de conversas com mulheres que gestaram e pariram entre a década de 1950 e 1970 expressam 
lembranças afetivas positivas quanto aos cuidados que receberam de Parteiras Tradicionais que atuavam no domicílio antes da institucionalização do parto.

Durante a Feira de Saúde da $5^{a}$ edição do Encontro de Turismo de Base Comunitária e Econo7mia Solidária (2015) em uma roda de mulheres do Beiru/Cabula, foi marcante o relato de D. a Bizinha, uma senhora muito alegre de 75 anos: "Vou te dizer uma coisa minha fia, eu pari nove fios, sete vingou e tá tudo aí pra vocês vê. Nasceram tudo em casa, mas tinha D. ${ }^{a}$ Tatá pra me acudir, o último derradeiro nasceu na fonte onde ía buscar água pra beber e lenha pra cozinhar. Meu marido me ajudava, era tudo ligeirinho e sem agonia, quando dava a dor de parir ele ia correndo chamar a D. ${ }^{a}$ Tatá pra pegar meu menino. Às vezes não dava nem tempo dela chegar, porque morava longe, aí quando chegava o menino já estava fora, aí cortava o imbigo, dava banho e deixava ele arrumadinho pra mim." Ao ser questionada sobre maternidades, Bizinha respondeu: "Oxe, era muito longe e nem tinha como chegar lá do outro lado da cidade."

O relato anuncia saberes e práticas tradicionais nascidas e perpetuadas na herança familiar através da experiência e da oralidade e representa parte importante da vida reprodutiva dessas mulheres. Falas como essa contam e recontam vivências de parto com sentimento de alegria e intimidade, representando parte da história que foi construída pela arte de partejar das Parteiras Tradicionais, presentes no seio das famílias até a institucionalização da assistência ao parto.

Assim, a memória presente nas histórias de vida, pode ser reconhecida como memória coletiva através do fio condutor das narrativas. Como afirma Souza (2007), a "memória narrativa" parte de um olhar sobre si para articular diferentes tempos e espaços, orientando a lembrança das experiências de vida: "As narrativas expressão vivências que são redimensionadas pelo ato de narrar [...]. Face aos desafios que se colocam entre o vivido, a memória e o narrado." (SOUZA, 2018 p. 17).

Reconstruir a história do parto assistido por parteiras no Cabula, busca romper com o silêncio de mulheres que guardam memórias de relevância social para o registro desse patrimônio que resiste à colonialidade. A pergunta inicialmente enunciada "Como as mulheres das comunidades do Cabula enunciam em suas narrativas, as vivências dos cuidados durante a gestação, parto e pós-parto?" se ramifica na busca pelos cuidados não institucionalizados, oferecidos na gestação, parto e pós-parto, os agentes de cuidado presentes e as memórias de cuidadoras tradicionais.

As narrativas valorizam a aproximação com os sujeitos constituindo um instrumento de compreensão da realidade contemporânea enquanto técnica e metodologia (ASPASIA; CAMARGO, 1954, apud GONÇALVES; LISBOA, 2007). Ligia Pereira (1991) defende a história oral na perspectiva sociológica como elemento essencial para obter bases coletivas da subjetividade, inerentes aos valores e opiniões para compreender a realidade social. Quando o vivido é recuperado, conforme concebido por quem viveu, o método remete aos espaços da memória (PEREIRA, 1991). Assim, a abordagem biográfica narrativa contribui para a compreensão daquilo que é singular nas histórias e memórias institucionais que revelam as práticas individuais nelas inscritas (SOUZA, 2007).

${ }^{7}$ Os nomes próprios citados são fictícios. 
A respeito de fragmentos de memórias, Muylaert e colaboradores (2014) destacam que este fenômeno é seletivo. Lembramos daquilo que podemos e esquecemos o que não é possível recordar, constituindo as narrativas de representações ou interpretações do mundo que não podem ser julgadas como verdadeiras ou falsas, expressando a verdade a partir de um ponto de vista de um determinado tempo, espaço e contexto sócio histórico. Existe uma relação proximal entre os termos memória e experiência, porque a memória se acumula ao longo dos anos e é processual, controlando a relação de sentidos entre uma experiência passada e presente (FERNANDES, 2003). As conversões verbais produzidas pela sociedade representam o quadro elementar e ao mesmo tempo estável da memória coletiva e a memória pessoal é também uma memória social, familiar e grupal (BOSI, 2016).

As ações extensionistas desenvolvidas no território do Cabula são fundamentais para o recorte da amostra da pesquisa, configurando articulações com associações e terreiros, mediados pelos parceiros de trabalho e relações de amizade construídas. Assim, serão escolhidas cerca de seis comunidades para iniciar o processo do trabalho de campo. O mesmo lançará mão das técnicas de grupo focal (GF) e entrevistas narrativas (EN).

Os GF viabilizarão a aproximação com as mulheres que farão parte da pesquisa por meio de EN. Essa técnica é apropriada para os casos em que o pesquisador busca identificar como uma determinada população interpreta e compreende o significado de algum fenômeno social: "Pressupondo que percepções, atitudes, opiniões e representações são socialmente construídas" (WESTPHAL; BÓGUS; FARIA, 1996). Os GF serão articulados da seguinte forma: 1) contato com as associações/comunidades-terreiro visando identificar as mulheres com perfil de contadoras de histórias; 2) contato prévio e/ou uma visita em seu domicílio para convidá-las a participar do GF; 3) realização do GF; 4) identificação das mulheres que permanecerão participando da pesquisa (critérios de inclusão: interesse e propriedade em torno das temáticas do estudo) e 5) agendamento das EN.

As EN possibilitam descrever as histórias de vida em profundidade, ressignificando as lembranças e memórias das entrevistadas. A característica singular da narrativa é estimular os sujeitos entrevistados a discorrer sobre fragmentos de sua vida e do contexto social. Elas podem potencializar e capturar circunstâncias as quais o pesquisador almeja investigar, porque as narrativas manifestam uma maneira singular da pessoa experienciar o mundo a partir de suas histórias, reconstruindo continuamente significados de si mesmo (MUYLAERT E COLABORADORES, 2014). A evocação da memória para a transmissão do vivido representa o elo fundamental para os estudos da história oral de vida e neste método, são valorizados os silêncios, os esquecimentos, as reiterações e a linguagem não verbal, esse grupo de elementos servirá para construir os dados para análise (SOUZA, 2007).

Para tratar os dados da pesquisa de campo será realizada análise de conteúdo, etapa importante que consiste numa técnica que organiza o conjunto das categorias enunciadas para dar significado ao produto obtido nas EN e descreve de forma objetiva e sistemática os conteúdos que emergiram da coleta. Assim, permite a representação dos conteúdos e elementos das mensagens de maneira rigorosa, por meio da sua codificação e classificação em categorias e subcategorias (AMADO, 2014). 
Para analisar e interpretar o material serão adotadas as três etapas sugeridas por Meihy (2005): a transcrição exaustiva do oral ao escrito, a textualização na qual as perguntas do pesquisador são retiradas ou adaptadas às falas das participantes e por último, a transcriação, que se refere à incorporação de elementos extratextos para composição das narrativas das mulheres/sujeitos da pesquisa.

Tomaremos como referência para análise dos dados, os conteúdos que serão extraídos nos GF e nas EN, com a mesma lógica que pretendemos aplicar durante todas as etapas deste projeto - o rigor e o compromisso ético com as mulheres que vão tecer em colcha de retalhos, os fragmentos de memória dos saberes sobre gestação, parto e pós-parto das mulheres do Cabula.

\section{CONCLUINDO... OU COMEÇO, MEIO E COMEÇO}

O território físico, espacial, histórico passa a ser agenciado simbolicamente pelas narrativas que comportam historicamente sua espacialidade, mas se manifestam para além dela. A narrativa passa a ser, portanto, um elemento essencial de transposição entre os tempos (passado, presente, futuro) e os espaços (originários, colonizados e contra coloniais) (NICOLIN, 2014; SANTOS, 2015).

Assim, cabe retomar a significação do quilombo enquanto modo de organização (acampamento) de resistência (guerreiro) no espaço físico e natural (floresta) para o percurso que buscamos até aqui e mais a frente trilhar: modos de narrar a contra colonização dos corpos autônomos indisciplinados das mulheres remanescentes quilombolas do Cabula. Tal trilha se cercará certamente das ferramentas disponíveis do modo acadêmico de entendimento do mundo, mas aceitando o mistério (o "cabula") na transposição dessa calunga grande (o grande mar e a transição entre a vida material e ancestral), queremos retomar nesse fim o início, pedindo aquelas e aqueles que vieram antes e que ocupam os lugares de fala aos quais nos reverenciamos: A bênção? Bandagira!? Agô!?

\section{REFERÊNCIAS}

ALMEIDA, Gabriel. Falamos em nosso próprio nome: estudantes do quilombo Cabula, $2007 . \quad$ Disponível www.cbg2014.agb.org.br/resources/.../1/1404308321_ARQUIVO CBG.pdf>. Acesso em: 03 jul. 2016.

Artigoda

AMADO, João (Coord.). Manual de Investigação qualitativa em educação. $2^{\mathrm{a} e d .}$ Coimbra: Universty Press, 2014.

BARROSO, Iraci. Os saberes de parteiras tradicionais e o ofício de partejar em domicílio nas áreas rurais. PRACS: Revista Eletrônica de Humanidades do Curso de Ciências Sociais da UNIFAP, № 2. dez. 2009.

BARRETO, Maria. Assistência ao nascimento na Bahia oitocentista. História, Ciências, Saúde -Manguinhos, Rio de Janeiro, v.15, n.4, p.901-925, 2008 
BERTAGNOLLI, Gissele. Da colonialidade à descolonialidade: diálogos de ciências a partir de uma "epistemologia do sul" - uma análise de comunidades quilombolas. Rev. Grifos, N. 38/39, 2015.

BERTOLDI, Márcia. Saberes tradicionais como patrimônio cultural imaterial dinamizador do desenvolvimento sustentável. Revista Novos Estudos Jurídicos, Itajaí, v. 19, n. 2 mai./ago., p. 559-584. 2014. Disponível em: < http://siaiap32.univali.br/seer/index.php/nej/article/view/ 6018/pdf_1 >. Acesso em: 06 nov. 2017.

BOSI, Ecléa. Memória e Sociedade: Lembranças de Velhos. 19ª ed. São Paulo: Companhia das Letras, 2016.

DAVIS-FLOYD, Robbie. The Technocratic, Humanistic, and Holistic Paradigms of Childbirth. International Journal of Gynecology and Obstetrics, Vol 75, Supplement No. 1, pp. S5-S23, November 2001.

EHRENREICH, Barbara e ENGLISH, Deirdre. Sorcières, sages-femmes et infirmières. Une histoire des femmes et de la médecine. Montreal: Les Éditions du remue-ménage, 1976.

FERNANDES, Rosali. Las políticas de la vivienda en la ciudad de Salvador y los processos de urbanizacíon popular en el caso del Cabula. Universidade Estadual de Feira de Santana, 2003.

FOUCAULT, Michel. O nascimento da clínica. Tradução. Roberto Machado. 5 ed. Rio de Janeiro: Forense Universitária. 2001.

Microfísica do Poder. Rio de Janeiro: Edições Graal, 2002.

FONTENELE, Rafael. et al. Fitoterapia na Atenção Básica: olhares dos gestores e profissionais da Estratégia Saúde da Família de Teresina $(\mathrm{PI})$, Brasil. Ciência e Saúde Coletiva, v. 18, n. 8, p. 2385-2394, 2013. Disponível em:<http://www.scielo.br/pdf/csc/v18n8/ 23.pdf>. Acesso em: 23 set. 2015.

GALVÃO, Mary. Memória de ritos e símbolos na prática das parteiras no Nordeste brasileiro. in: Brasil, espaço memória e identidade. In: LEMOS, M.T.T.B; BAHIA, L.H.N; Dembcz A, editores. Warszawa: CESLA; 2001. p. 261.

GONÇALVES, Rita; LISBOA, Teresa. Sobre o método da história oral em sua modalidade trajetórias de vida. Rev. katálysis [online]. 2007, vol.10, n.spe, pp.8392. ISSN 1982-0259. Disponível em: <http://dx.doi.org/10.1590/S141449802007000300009 .>. Acesso em: 28 jun. 2018.

GOUVEIA, Anneza. Um olhar sobre o bairro: aspectos do Cabula e suas relações com a Cidade de Salvador / Anneza Tourinho de Almeida Gouveia: Salvador, 2010.

GROSFOGUEL, Ramón. Para descolonizar os estudos de economia política e os estudos pós-coloniais: transmodernidade, pensamento de fronteira e colonialidade global. Revista Crítica de Ciências Sociais, 2008. 
LANDER, Edgardo. "Ciências sociais: saberes coloniais e eurocêntricos", em: E. Lander (organizador), A colonialidade do saber. Eurocentrismo e ciências sociais. Perspectivas latino-americanas, Buenos Aires: Conselho Latino-americano de Ciências Sociais (CLACSO), 2005.

MARIN, Raquel; COMIN, Fábio. Desfazendo o "Mau-olhado": magia, saúde e desenvolvimento no ofício das benzedeiras. Psicol. cienc. prof. [online]. 2017, vol.37, n.2, pp.446-460. ISSN 1414-9893. Disponível e: < http://dx.doi.org/10.1590/1982-37030023520 16> Acesso em: 11 jun. 2018.

MEIHY, José. Manual de História Oral. 5. ed. São Paulo: Loyola, 2005.

MELO, Camila Pimentel Lopes de. A (des)colonialidade do parto: reflexões sobre o movimento de humanização da parturição e do nascimento. 2013. Apresentação de Trabalho/ Congresso. Disponível em: <actacientifica.servicioit.cl/biblioteca/gt/GT6/GT6_PimentelLopesDeMelo. pdf>. Acesso em: 10 jul. 2017.

MIGNOLO, Walter. A colonialidade de cabo a rabo: o hemisfério ocidental no horizonte conceitual da modernidade. In: LANDER, E. (Org.). A colonialidade do saber: eurocentrismo e ciências sociais. Perspectivas latino-americanas. Buenos Aires: Clacso, 2005.

MOTT, Maria. Assistência ao Parto: do domicilio ao hospital (1830-1960). Proj. Hitória, São Paulo, 2002.

MUNANGA, Kabengele. Negritude: usos e sentidos. São Paulo: Ática, 1988.

MUYLAERT, Camila Junqueira et al. Entrevistas narrativas: um importante recurso em pesquisa qualitativa. Rev Esc. Enferm. Univ. São Paulo. 2014. Disponível em: <http://www.scielo.br/ pdf/reeusp/v48nspe2/pt_0080-6234reeusp-48-nspe2-00184.pdf> Acesso em: 27 Jul. 2016.

NASCIMENTO, Wanderson. Por uma vida descolonizada: Diálogos entre a bioética de intervenção e os estudos sobre a colonialidade. Tese (Doutorado em Bioética) - Universidade de Brasília, Brasília, 2010.

NICOLIN, Janice de Sena. Ecos que entoam uma mata africano-brasileira. Salvador: Edufba, 2014.

. Kipovi Cabuleiro: Um tom de Memória do Cabula. 2016. 290 f. Tese (Doutorado em Educação e Contemporaneidade) - Universidade Estadual da Bahia, Salvador, 2016.

OLIVEIRA, Luiz; CANDAU, Vera. Pedagogia decolonial e educação antirracista e intercultural no brasil. Educação em Revista. Belo Horizonte, v.26, n.01, p.1540, abr. 2010

PEREIRA, Ligía. Relatos orais em ciências sociais: limites e potencial. Análise \& Conjuntura, v. 6, n. 3, Belo Horizonte, Set/Dez, 1991. 
QUIJANO, Aníbal. Colonialidade do poder, eurocentrismo e América Latina. En libro: A colonialidade do saber: eurocentrismo e ciências sociais. Perspectivas latino-americanas. Edgardo Lander (org). Colección Sur Sur, CLACSO, Ciudad Autónoma de Buenos Aires, Argentina. setembro 2005. pp.227-278. Disponível em: <http://biblioteca virtual.clacso.org.ar/ar/libros/lander/pt/Quijano.rtf>. Acesso em:16 jun. 2017.

RAMOS, Ticiana Osvald. Casas de parto autônomas no contexto brasileiro: conflitualidades e sentidos em torno da humanização de partos e nascimentos. 2013. 351 f. Tese (Doutorado em Ciências Sociais) - Universidade de Brasília, Brasília, 2013.

ROCHA, Mônica; SILVA, Francisca. Saberes Populares sobre Saúde no Distrito Sanitário Cabula/Beiru. 69a Reunião Anual da SBPC - 16 a 22 de julho de 2017 - UFMG - Belo Horizonte/MG. 1. 6.13.99 - Turismo.

ROSA, Wanderleia. Rezas, Rezadeiras e Juventude na Comunidade Vão de Almas, Cavalcante - GO. 2013. 55 f. Trabalho de Conclusão de Curso (Licenciatura em Educação do Campo) - Faculdade UNB de Planaltina - FUP, Platina/DF, 2013.

SEGATO, Rita. Que cada povo teça os fios da sua história: o pluralismo jurídico em diálogo didático com legisladores. Direito.UnB, Revista de Direito da Universidade de Brasília janeiro - junho de 2014, v. 01, n.01.

SANTOS, Antônio Bispo dos. Colonização, quilombos: modos e significados. Brasília. Editora UnB, 2015.

SILVA, Valdélio. Rio das rãs à luz da noção de quilombo. 2000. In "Do Mucambo do Pau-Preto a Rio das Rãs. Liberdade e escravidão na construção da identidade negra de um quilombo contemporâneo. Dissertação (Mestrado em Sociologia) - Universidade Federal da Bahia, Salvador, 1998. Disponível em: <https://portalseer.ufba.br/index.php/afroasia/article/ view/20987/13588.>. Acesso em: 19 de mar. de 2017.

SILVA, Itala. A relação conflituosa entre médicos e enfermeiras no contexto hospitalar. Tese (Doutorado em Ciências Sociais) - Universidade Católica de São Paulo, São Paulo, 2006.

SOARES, Danieli. Descolonialidade do saber e a vivência das parteiras no estado de Pernambuco: Um prisma a partir dos estudos pós-coloniais. Tese (Doutorado em Ciências Humanas, Letras e Artes) - Universidade Federal da Paraíba, João Pessoa/PB, 2016.

SOUZA, Elizeu Clementino de. (Auto)biografia, histórias de vida e práticas de formação in NASCIMENTO, A. D; HETKOWSKI, T. M. (orgs). Memória e formação de professores [online]. Salvador: EDUFBA, 2007. 310 p. ISBN 97885-232-0484-6. Available from SciELO Books . 
O que será que será? Estigmas, refiguração identitária e narrativas biográficas. In: SOUZA, Elizeu Clementino de; VICENTINI, Paula Perin e LOPES, Celi Espassandin (orgs.). Vida, narrativa e resistência: Biografização e empoderamento. Curitiba: Editora CRV, 2018.

TORRES, Nelson. A descolonização e o giro descolonial. Tabula Rasa [online]. 2008, n.9, pp.61-72. ISSN 1794-2489. 2008.

VIEIRA. Elisabeth. A medicalização do corpo feminino, In K Giffin \& SH Costa. Questões da saúde reprodutiva. Fiocruz, Rio de Janeiro, p. 67-78,1999.

WALSH, Catherine. Interculturalidad, plurinacionalidad y decolonialidad: las insurgencias político-epistémicas de refundar el Estado. Tradução de João B. A. Figueiredo Tabula Rasa. Bogotá: Colombia, n. 9: 131-152, jul-dez 2008.

WESTPHAL, Marcia; BÓGUS, Claúdia; FARIA, Mara. Grupos focais: experiências precursoras em programas educativos em saúde no Brasil. Bol Oficina Sanit Panam, 1996. 